\title{
Research on Further Design-----Taking the Coffee Maker Design as an Example
}

\author{
Zhao Zhanfeng \\ Wenzhou Vocational \& Technical College, Wenzhou, 325035 \\ Zhanfeng@qq.com
}

Keywords: coffee maker, design, research

Abstract: The further design of the coffee maker conforms to the trend of the current product design, breaks the traditional perception of the shape and functions of the coffee maker, makes the coffee maker more beautiful and practical, and better meets the requirements of the consumers for diversified coffee makers. Especially its humanized and emotional design makes the product better conform to the human engineering. By performing creative design on the appearance of the coffee maker; the machine will be combined with feeling of the human, thus guiding the integration of individuality and emotional needs.

\section{Market survey for the coffee maker}

\subsection{Function survey for the coffee maker}

Based on the survey in the market, most of the coffee makers have the following basic functions such as grinding, power loading, power pressing, and brewing, extracting and residual cleaning. But in actual operation, there are several problems, such as complicated operation, inconvenient use, weak operation indication, and incomplete user functions. All these need to be considered for design improvement. Figure 1 shows the separable filter holder, and figure2, the LED indicator.

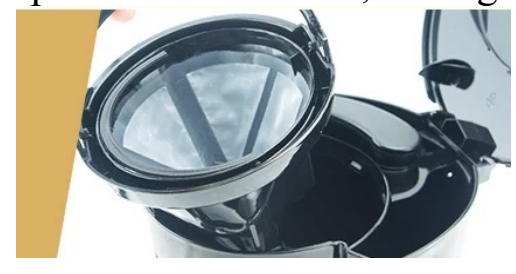

Figure 1 Separable filter holder

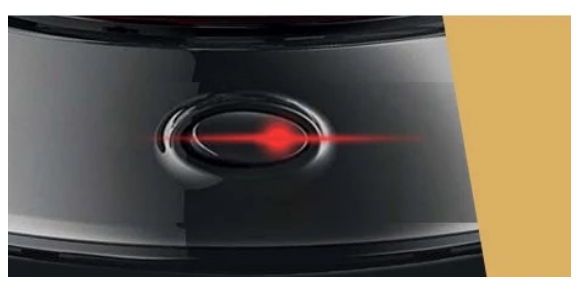

Figure 2 LED indicator 


\subsection{Survey on coffee maker material}

Most of coffer makers are made of metal and plastic. The metal material is hard, gloss, with good electric conduction and thermal conductivity, but the cost is much higher. The plastic one is light, firm, waterproof, anti-corrosion, with low price, which is easy to get.

\subsection{Survey on the coffee maker color}

There are a variety of colors for the coffee maker. Some use dark deep color while others use happy bright color. And most of coffee makers use dark grey color.

\section{Analysis on human machine size for the coffee maker}

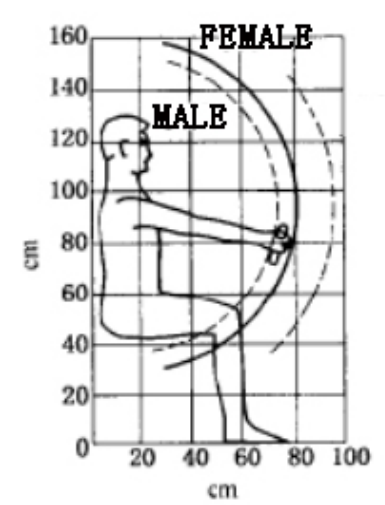

Figure 3 Human machine analysis charts

The survey for the size of coffee maker should not only consider the overall size of the coffee maker, but also the height size of the coffee cup. Figure 3 displays the arm activity range according to the human engineering. In general, the length, width and height of the family use coffee maker are within $250 \mathrm{~mm}$ to $400 \mathrm{~mm}$, while the length of the commercial use coffee maker is about $80 \mathrm{~mm}$, width and height is from 120 to $140 \mathrm{~mm}$. The coffee cup can be divided into three sizes: big, middle and small, and the big one is above $300 \mathrm{ml}$, the middle one is 120 to $140 \mathrm{ml}$ and the small one is 50 to $80 \mathrm{ml}$.

\section{Analysis of advantages and disadvantages for the coffee maker}

Most of the coffee makers in the market are clumsy in appearance without delicate and exquisite style. Besides, the coffee maker cleaning and residual treatment are not handled reasonably, which cause difficult cleaning and resource waste for the sticky residual. At the same time, they are only designed as a machine to make coffee without humanized and emotion design, thus making the coffee maker cold lack of tender and emotional feeling.

\section{Initial design plan}

\subsection{Specific location for the design}

The design is located on the appearance of the family use automatic coffee maker.

The coffee maker is mainly made of plastic or metal material. To attract consumers, designers should utilize the shape and texture to express style, and apply color to express emotion. As a technical product, the coffee maker in general will use cold grey hue. 
The design of the coffee maker embodies "people first" concept. For the coffee maker design, people should conduct some survey and research on the common comfort using methods, such as griping and opening, to make the coffee maker better meet the needs of the human machine engineering.

\subsection{Free hand scratch}

Free hand scratch is an initial expression of the design and is a visualization of the thinking. Based on the brainstorm, the developed design has formed into the initial product with creation and imagination. So the molding language of the coffee maker design is determined by integrating design concept as displayed in figure 4.

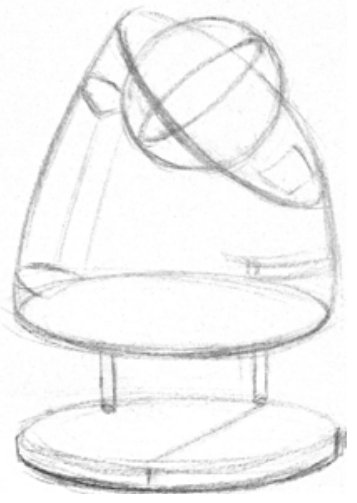

Figure 4 sketch 1

The bean container is designed as a sphere with transparent material. Intelligent display is under the inclined plane, water tank is on the side, and water collector basin and heat preservation basin are underneath the inclined plane. The height can be adjusted by using the tensile structure, and the machine can be covered when it is not used.

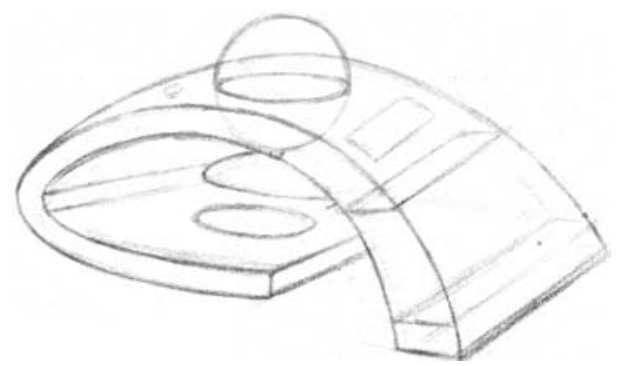

Figure 5 sketch 2

The use of curved design implies the silk smooth flavor of the coffee. By taking mismatch shape, it gives people a twisting feeling. By adding the rubber pad at the turning part, the machine can be hung to the same space when it is not used, as shown in figure 5.

\section{Further design of the plan}

\subsection{Sketch modification and further design}

As figure 6 shows, perform further design and perfection to the selected plan, make the molding language and detail is more clear and determined. 


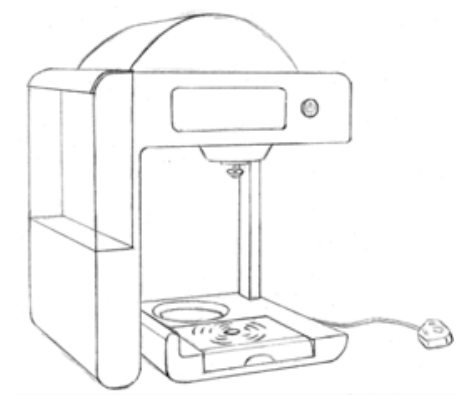

Figure 6 Further design of the sketch

Considering the human engineering, single pole support is used at the right side of the coffee maker. It will strengthen stability for the whole coffee maker, and provide more convenience for the people to put the coffee cup. As for the function, the coffee maker adopts huge touch screen so as to reduce the number of buttons. In addition, the anti-leakage design is used on the outlet of the coffee maker to avoid the coffee splashing. There are water basin and heat preservation basin for the base basin, with the heat preservation basin used for keeping flavor and temperature of the coffee.

\subsection{Drawing of six views}

Analysis is conducted for the size of overall machine and each part based on market survey and human engineering. The overall size of the machine is $270 \mathrm{~mm}$ in length, $220 \mathrm{~mm}$ in width, and 350 $\mathrm{mm}$ in height. The size of the water collection basin is $120 \mathrm{~mm}$ in length, $110 \mathrm{~mm}$ in width and the distance between the drip nuzzle and the basin is $160 \mathrm{~mm}$, as displayed in figure 7,8 .
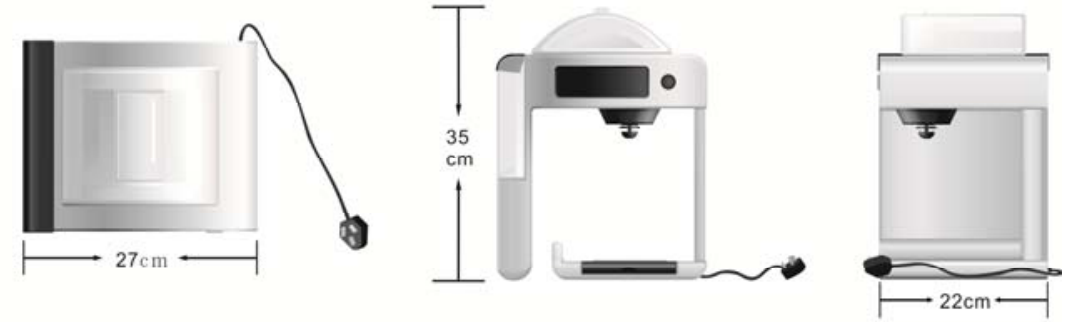

Figure 7 Dimension drawing of the coffee maker
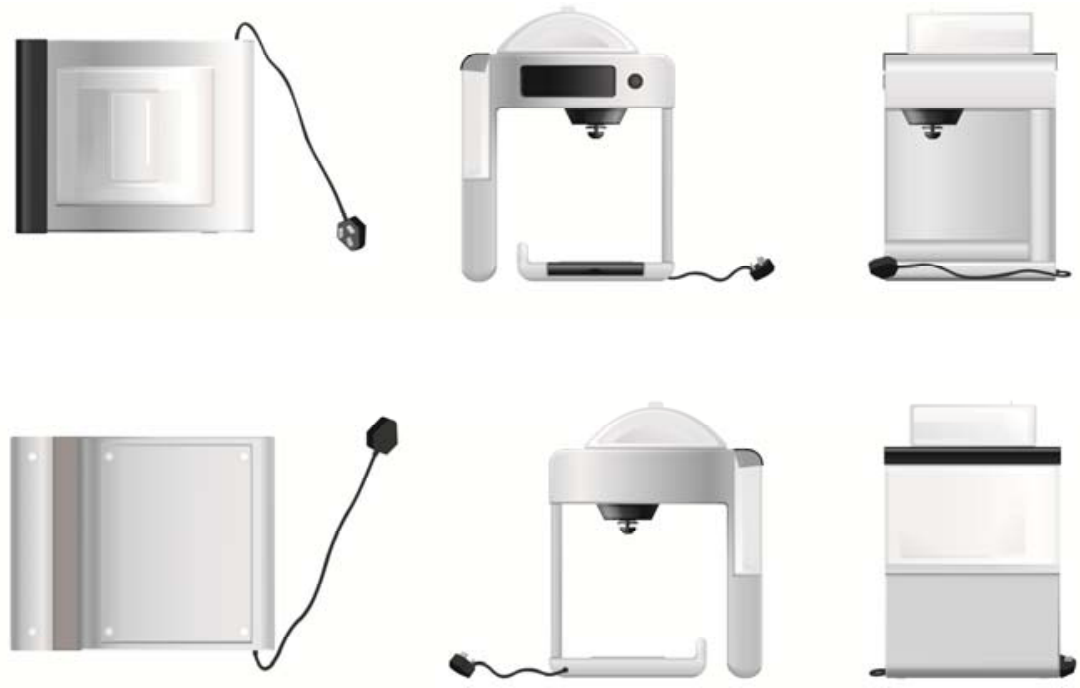

Figure 8 Six views of the coffee maker 


\subsection{Three dimensional modeling}

Select one preferred plan from the two designs. Then based on the defined size, the author designed a product effect picture, and six views perform three dimensional modeling, so as to change the design of the coffee maker from a plane graph to a solid one. This can observe the shape and internal structure of the coffee maker more directly, thus is helpful to verify its reasonability further.

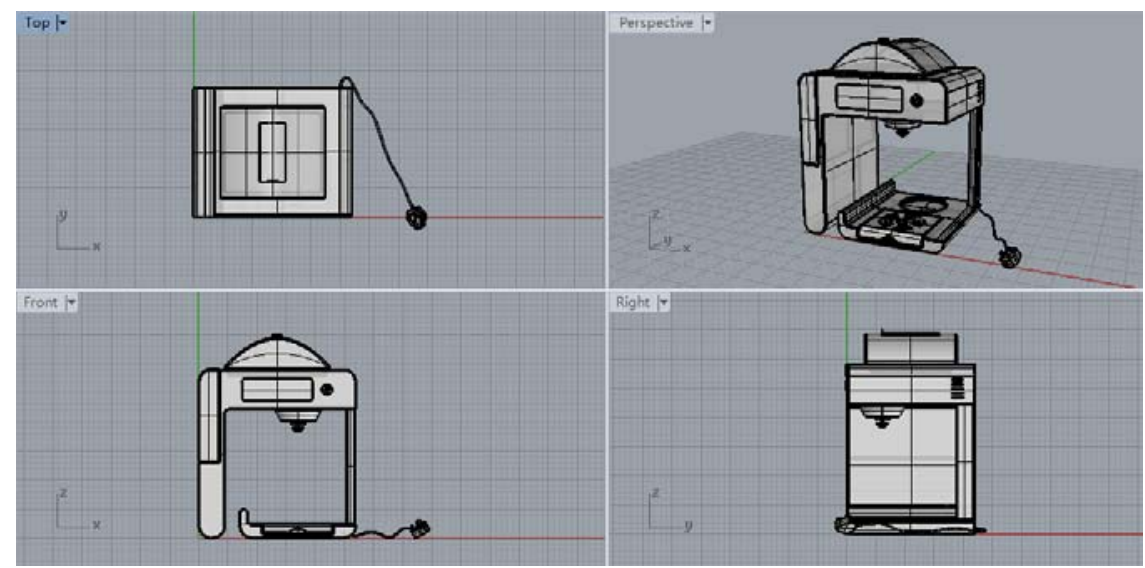

Figure 9 Modeling one

\subsection{Color plan and rendering picture}

Perform rendering to the material and color of the three-dimensional graph of the coffee maker.
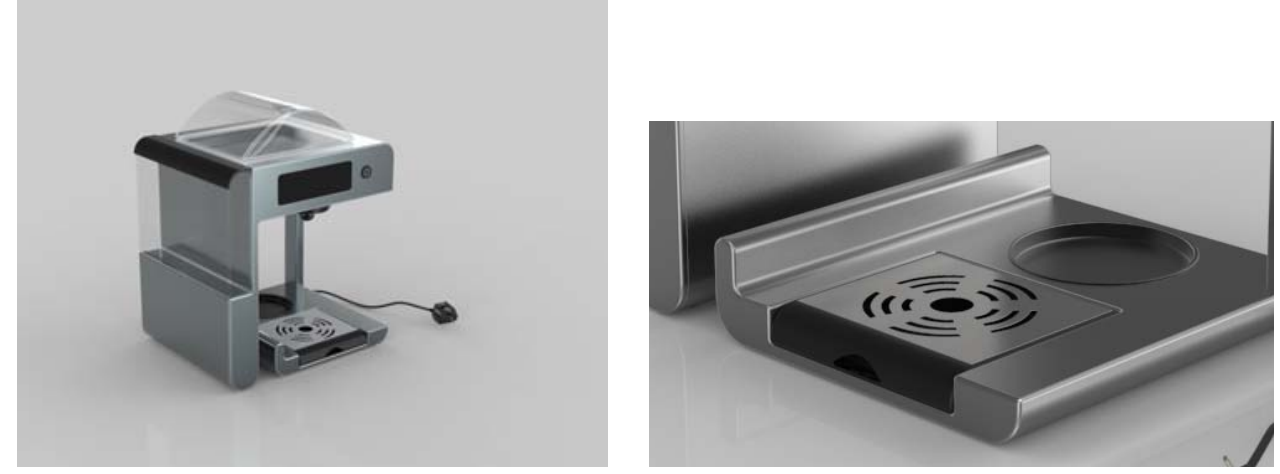

Figure 10 Rendering picture and detailed drawing

\section{Conclusion}

For the design of the appearance of the coffee maker, it needs not only careful study on the overall shape, but also needs more attention to the material contrast and color matching. At the same time, it needs some assistant designs to improve the function of the coffee maker.

\section{References}

[1] NORMAN D A. Emotional Design[M]. Beijing: Electronic Industry Press, 2007.

[2] Jin Xinmin, Wu Jianing. Environment-friendly Design of Home Shopping Cart[J]. Packaging Engineering, 2010, 31(16):8.

[3] Lu Xiaobo, Zhao Chao. Industrial Design Program and Methods[M]. Beijing: Tsinghua University Press, 2010.

[4] Xu Qingtao. The Image of the Product Design [J]. Packaging Engineering,2009,30(6):62 -63. 
[5] Dong Shihai, Wang Heng. The Interaction between Man and Machine[M]. Beijing:Peking University Press,2011.

[6] Sun Xiaoman. Research on Entertaining Products Design Concerning about the Olds'Emotional Life [D]. Tianjin: Hebei University of Technology,2011.

[7] Yao Hongting. On Integration of New Media Art with Product Design for Senior Citizens[J]. Design Research, 2012(2):113-116.

[8] Luo Jingyan. Home Welfare Products Design for Older Users[J]. Packaging Engineering, 2014,35(10):42—45. 